\title{
Spring temperatures in the Sagehen Basin, Sierra Nevada, CA: implications for heat flow and groundwater circulation
}

\author{
MARIA BRUMM, CHI-YUEN WANG AND MICHAEL MANGA \\ Earth and Planetary Science, University of California, Berkeley, CA, USA
}

\begin{abstract}
Heat flow in the Sierra Nevada, CA, is low despite its young geologic age. We investigate the possibility that advective heat transport by groundwater flow leads to an underestimate of heat flow in the Sierras based purely on borehole measurements. Using temperature and discharge measurements at springs in Sagehen Basin, we find that groundwater removes the equivalent of approximately $20-40 \mathrm{~mW} \mathrm{~m}^{-2}$ of geothermal heat from the basin. This is comparable with other heat flow measurements in the region and indicates that, in this basin, at least, groundwater does transport a significant amount of geothermal heat within the basin. Additionally, we use estimates of the mean residence time of water discharged at the springs along with hourly temperature records in springs to provide constraints on groundwater flow depths within the basin. An analytical model based on these constraints indicates that the heat removed by groundwater may represent $20 \%$ to $>90 \%$ of the total heat flow in the basin. Without better constraints on the regional hydrogeology and the depth of circulation, we cannot determine whether the heat discharged at the springs represents a change in the mode of heat transfer, i.e. from conduction to advection at shallow depths $(<100 \mathrm{~m})$ or whether this is a component of heat transfer that should be added to measured conductive values. If the latter is true, and Sagehen Basin is representative of the Sierras, basal heat flow in the Sierra Nevada may be higher than previously thought.
\end{abstract}

Key words: heat flow, recharge, Sierra Nevada, springs

Received 9 May 2008; accepted 18 June 2009

Corresponding author: Chi-Yuen Wang, Earth and Planetary Science, University of California, Berkeley, CA, USA. Email: chiyuen@berkeley.edu. Tel: +1 510642 2288. Fax: +1 5106439980.

Geofluids (2009) 9, 195-207

\section{INTRODUCTION}

Groundwater circulation can have a significant influence on geothermal regimes. Advective heat transport by groundwater has long been recognized as an important factor in large sedimentary basins (see summary in Smith \& Chapman 1985) where length scales and permeabilities are large enough for free convection to occur. Although free convection does not typically happen in mountains, the large hydraulic gradients associated with high-relief topography can cause a transition to advectively disturbed thermal regimes at permeabilities as low as $10^{-18} \mathrm{~m}^{2}$ (Forster \& Smith 1988). Advective disruption of the geothermal regime has been identified at depths exceeding $500 \mathrm{~m}$ in a range of geological settings (Ingebritsen et al. 1989; Bodri \& Rybach 1998; Manga 1998).

Here, we investigate the possibility that heat advection by groundwater is responsible for an apparently low surface heat flow in the Sierra Nevada. As the regional hydrogeology and hydrogeologic properties are not constrained by modeling and borehole measurements, we rely on measurements made at springs which provide an integrated perspective on hydrogeologic processes (Manga 2001). We use data from nine springs to estimate the geothermal heat flow in a hydrologic basin in the northern Sierra Nevada, and obtain a value of approximately $20-40 \mathrm{~mW} \mathrm{~m}^{-2}$ for the heat removed advectively by groundwater. This is similar to heat flow measured in boreholes elsewhere in the Sierra Nevada (Saltus \& Lachenbruch 1991) and indicates that in this basin, at least, groundwater flow may transport a significant fraction of geothermal heat.

Additionally, we use an analytical model of heat flow within an aquifer to estimate the proportion of total heat flow represented by this value. The proportion of heat advected by groundwater is sensitive to the flow depth, and it is possible that the total heat flow in the Sierra Nevada is much larger than previously thought. 


\section{Heat flow in the Sierra Nevada}

Heat flow measurements in the Sierra Nevada are among the lowest seen on continents, similar to Precambrian continental shield, e.g. approximately $40 \mathrm{~mW} \mathrm{~m}^{-2}$ in the Canadian Shield, and approximately $50 \mathrm{~mW} \mathrm{~m}^{-2}$ in the Kaapvaal craton (Jaupart \& Mareschal 1999). As the heat flow of a geologic province is often related to its tectonic activity (Carlson et al. 2005), this low heat flow is seemingly at odds with evidence of Mesozoic to Cenozoic tectonic activity in the Sierras.

Saltus \& Lachenbruch (1991) presented a compilation of heat flow measurements in the Sierra Nevada (including work of Lachenbruch 1968; Roy et al. 1968; Lachenbruch et al. 1976). Most of the measurements are from depth intervals between about 100 and $250 \mathrm{~m}$. Inferred heat flow values show a linear relationship with heat production. Excluding sites near the magmatically active Long Valley, heat flow in the Sierra Nevada varies from approximately 20-80 $\mathrm{mW} \mathrm{m}^{-2}$, with the highest heat flows found closest to the Basin and Range province (Saltus \& Lachenbruch 1991). The data in the Sierra Nevada, combined with estimates of heat production within the batholith, are consistent with a mantle heat flow of less than $20 \mathrm{~mW} \mathrm{~m}^{-2}$ (Brady et al. 2006).

Changes in the thermal regime beneath the Sierran batholith would take tens of millions of years to be conductively transmitted to the surface; so, the low heat flow in the Sierra Nevada is commonly thought to be a transient state resulting from low-angle subduction of the Farallon slab (Roy et al. 1972; Dumitru 1990; Saltus \& Lachenbruch 1991; English et al. 2003; Erkan \& Blackwell 2006). English et al. (2003) calculated steady-state temperature profiles for possible models of flat-slab subduction, and found geothermal gradients ranging from 3 to $20^{\circ} \mathrm{C} \mathrm{km}^{-1}$ (equivalent to $8-50 \mathrm{~mW} \mathrm{~m}{ }^{-2}$ ) at the approximate location of the Sierra Nevada approximately $200 \mathrm{~km}$ inland from the trench. These values are consistent with modern heat flow observations.

\section{STUDY AREA}

Sagehen Basin is a $27-\mathrm{km}^{2}$ basin that lies on the east side of the Sierra Nevada crest, in Nevada County, California (see Fig. 1). Elevation within the basin ranges from $2660 \mathrm{~m}$ along Carpenter Ridge to the south-west to $1926 \mathrm{~m}$ at the Sagehen Creek gauging station. The mean annual temperature measured at the University of California, Berkeley research station (elevation $1932 \mathrm{~m}$ ) is $5.2^{\circ} \mathrm{C}$; the mean annual precipitation is $85 \mathrm{~cm}$, which falls mainly as snow during the months of October to April (Western Regional Climate Center station 047641, http:// www.wrcc.dri.edu/cgi-bin/cliMAIN.pl?ca7641). Figure 2 shows the location of the weather stations and the springs studied.
Alluvium, colluvium and glacial drift cover most of the basin, overlying Miocene and Pliocene andesite flows and pyroclastic deposits (Saucedo \& Wagner 1992; Sylvester 2007). These volcanic rocks outcrop only at higher elevations and in some areas north of Sagehen Creek. The andesite flows have thicknesses of approximately 10-100 m and the pyroclastic deposits are a few hundreds of meters thick (Sylvester 2007). Granodiorite underlies the volcanic rocks and is also present in the glacial till.

Groundwater chemistry in the Sagehen Basin is primarily controlled by mineral weathering of andesitic and granodioritic bedrock and soils (Rademacher et al. 2001), and there is little seasonal variation in spring chemistry (Erman \& Erman 1992). Spring water chlorofluorocarbon (CFC) ages vary from approximately 10 to 45 years (Rademacher et al. 2001) and the mean CFC residence time of water in Sagehen Creek during periods of base flow is 28 years (Rademacher et al. 2005). Apparent spring water ages remained constant over a 6-year sampling period (Rademacher et al. 2005; Blumhagen \& Clark 2008) and the springs retained their relative ordering with respect to chemical concentrations over the course of an 8-year drought cycle (Erman \& Erman 1992), indicating that a stable groundwater flow system feeds the springs. In this study we adopt the spring numbering system established by Erman \& Erman (1992) (see Fig. 2).

\section{DETERMINING HEAT DISCHARGE IN SPRINGS}

To find the geothermal heat discharged by a spring, we must know the amount of water discharged, its temperature at the discharge point and its temperature when it initially entered the aquifer. We can measure discharge and temperature directly but must use other methods to determine the recharge temperature. Here, we assume that the stable isotope composition of spring water reflects the elevation from whence it came, allowing us to use a correlation between elevation and temperature to determine the initial recharge water temperature. Additionally, we account for heating via the viscous dissipation of gravitational potential energy as water flows from its recharge elevation to the spring (Manga \& Kirchner 2003).

\section{Spring temperatures}

In the winter of 2004, we installed temperature probes (HOBO Water Temperature Probe from Onset) in eight springs to record the water temperature hourly. Probes were placed as near to the point of discharge as possible, tied to weights and fixed points outside the spring pools to keep them in place over the season. In the summer of 2005 , we returned, recovered two probes (the others had been washed away by spring floods) and replaced the lost probes. We recovered seven probes in the summer of 2006 
Fig. 1. Location of Sagehen Basin and nearby features. Weather stations used to determine the regional relationship between temperature and elevation are shown as red circles and the basin is shown by a heavy black line.

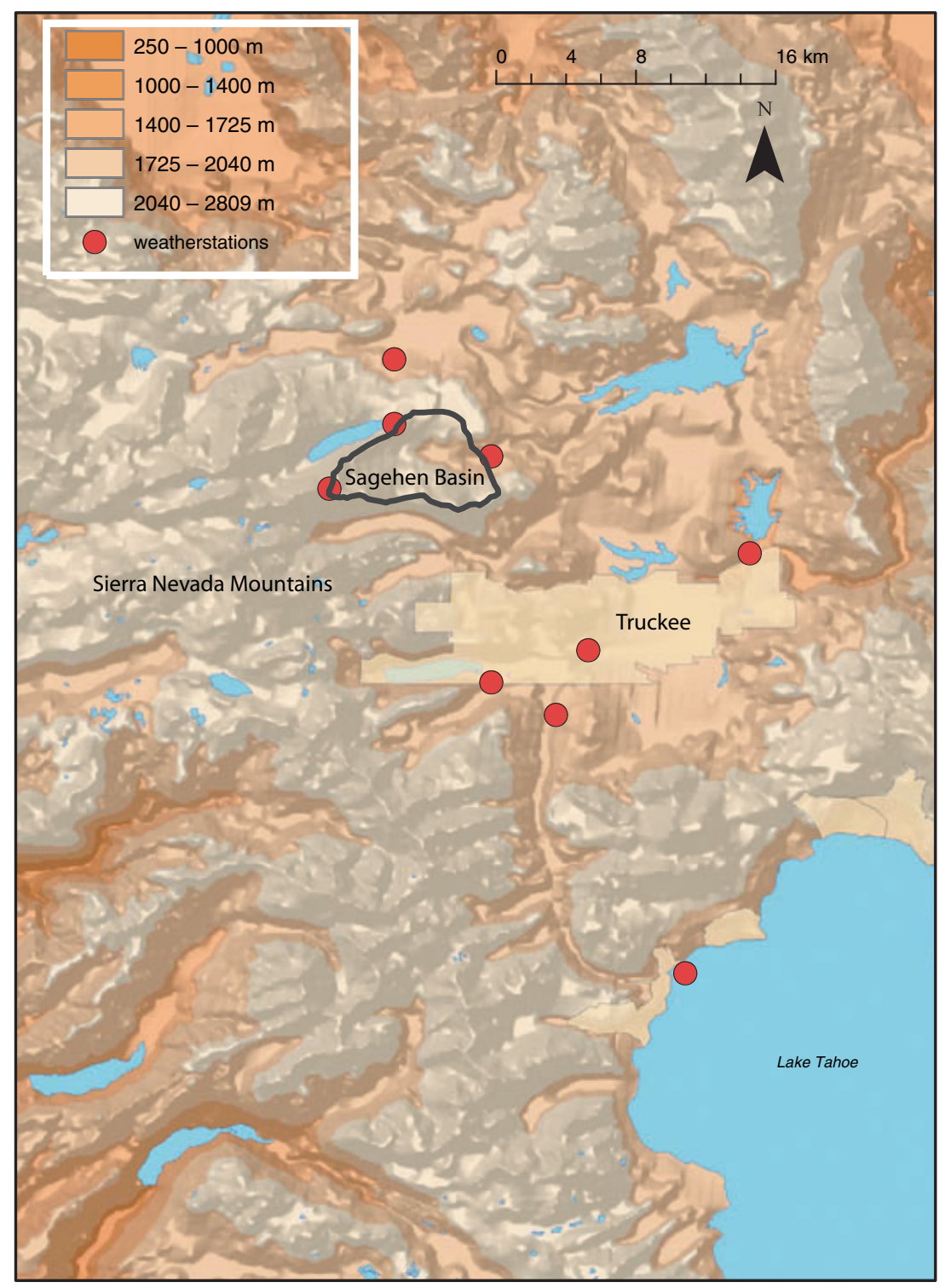

(all probes except that placed at Spring 5). Temperature records for selected springs are shown in Fig. 3.

Although spring temperatures responded to episodes of snow fall and snow melt, the springs also exhibit a steady base temperature that is insensitive to climatic fluctuations, and is in good agreement with previous measurements (Erman \& Erman 1992; Rademacher et al. 2001). As observed spring temperatures are consistent over time, we also used temperature data from Erman \& Erman (1992) and Rademacher et al. (2001).

\section{Recharge elevation}

The variation in oxygen isotope composition of precipitation is dominated by Rayleigh fractionation during evaporation and condensation, as heavier isotopes preferentially partition into the liquid phase. In nearly every region of the world, $\delta^{18} \mathrm{O}$ and $\delta D$ decrease with elevation (Poage \& Chamberlain 2001). Smith et al. (1979) found a lapse rate for deuterium in precipitation of $17.8 \pm 0.2 \%$ per $\mathrm{km}$ in stations immediately east of the Sierra crest; these data are presented in Fig. 4.

We collected samples of spring water for stable isotope analysis during the summer of 2005. Water was sampled from as near to the point of discharge as possible. Measured $\delta D$ and $\delta^{18} \mathrm{O}$ values of springs in Sagehen Basin are shown in Fig. 5. Spring water in the Sagehen Basin falls on or near the meteoric water line. Furthermore, spring temperatures are low, and water in these springs has a short residence time of 10-40 years (Rademacher et al. 2001, 2005). We therefore expect that water-rock interactions have had little effect on the isotopic composition of the 


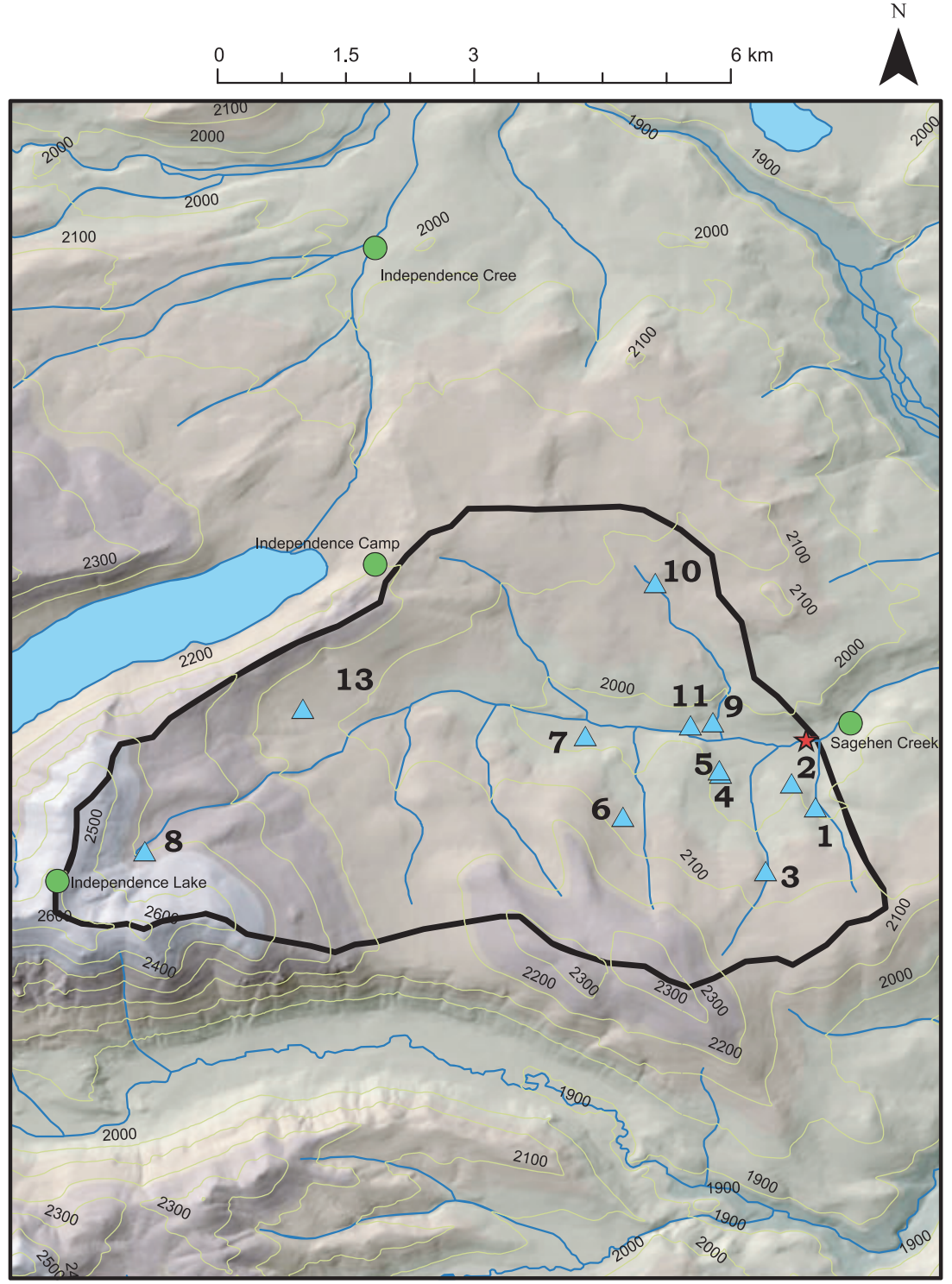

Fig. 2. Sagehen Basin showing spring locations with blue triangles. Numbers next to spring locations identify the spring numbers referred to in the text and tables. The stream gauge is marked by a red star and weather stations are marked by green circles. The approximate outline of the basin is denoted by a heavy black line. Contour interval is $100 \mathrm{~m}$. spring water, and stable isotopes in spring water should be comparable to precipitation.

Using the global meteoric water line $\left(\delta D=8 \delta^{18} \mathrm{O}+10\right.$; Craig 1961), the lapse rate of $\delta D$ measured by Smith et al. (1979) is equivalent to an oxygen lapse rate of $2.2 \pm 0.03 \%$ per $\mathrm{km}$. As the lapse rate determined by Smith et al. (1979) was found further south in the Sierra Nevada than Sagehen Basin, we do not directly apply this lapse rate to infer a recharge elevation for the spring water. Instead, we calibrate the relationship against Spring 8 . Spring 8 has the highest elevation $(2394 \mathrm{~m})$ of the springs in the study, and its water is the youngest (approximately 10 years, Rademacher et al. 2001); we therefore assume that its recharge elevation is similar to, but slightly higher than, $2394 \mathrm{~m}$. Using the $\delta^{18} \mathrm{O}$ and elevation of Spring 8 and a lapse rate of $2.2 \%$ per $\mathrm{km}$, we construct a lower bound relation for the stable isotope composition of precipitation in the Sagehen Basin.

Data from this study and Rademacher et al. (2002), however, show that differences between spring stable isotope compositions over time are larger than the analytical error. Therefore, we used the standard deviation of all available $\delta^{18} \mathrm{O}$ data for each spring as an estimate of error. Using a lapse rate of $2.2 \%$ per $\mathrm{km}$ to propagate this uncertainty, the error in recharge elevation associated with the laboratory analytical error of isotope values is about $10 \mathrm{~m}$. The error in recharge elevation associated with observed year-to-year changes in spring $\delta^{18} \mathrm{O}$ is many tens of meters for most springs but up to a few hundred meters for some springs. The greatest source of error for most springs is the uncertainty in the deuterium lapse rate. Estimated recharge elevations for each spring are shown in 

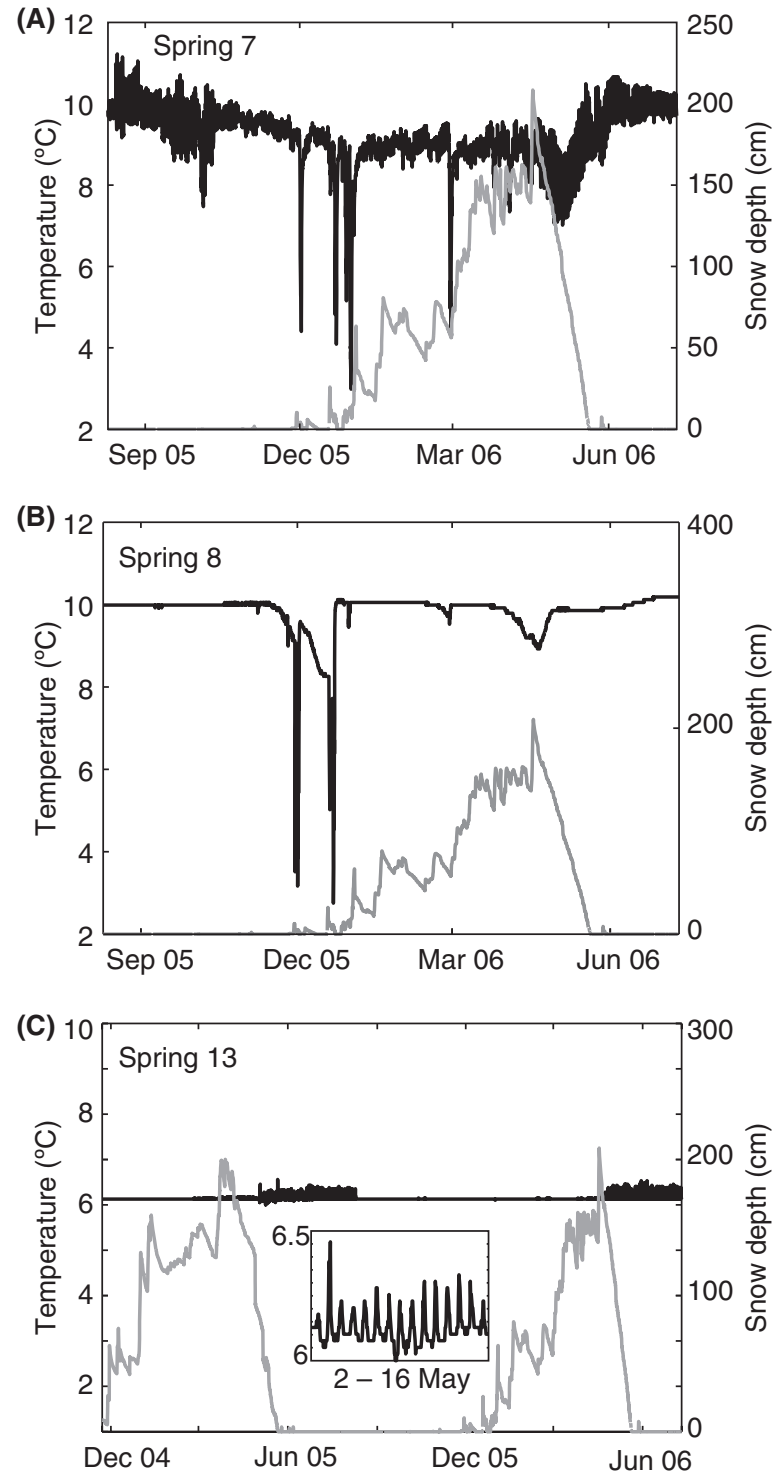

Fig. 3. Temperature in selected Sagehen Basin springs. Black lines show spring temperatures, and gray lines show snowpack depth at the Sagehen weather station (1930 m above m.s.l.). (A) Despite having the largest discharge, Spring 7 experienced significant temperature variation in response to both seasonal temperature changes and snowfall. (B) The probe at Spring 8 was set in a shallow pool, which experienced a strong response during the season's first snowfalls, presumably due to snow directly cooling the pool. Apart from these events, however, the temperature was steady. (C) Spring 13. Observed temperature variations during snow melt are diurnal fluctuations; inset figure shows temperature for 2 weeks in May 2005.

Table 2. Details of the error calculation are provided in the Appendix.

\section{Recharge temperature}

The range of mean annual air temperature at nine weather stations east of the Sierra crest is shown in Fig. 6 - see Fig. 1 for station locations. The wide spacing of the sta-

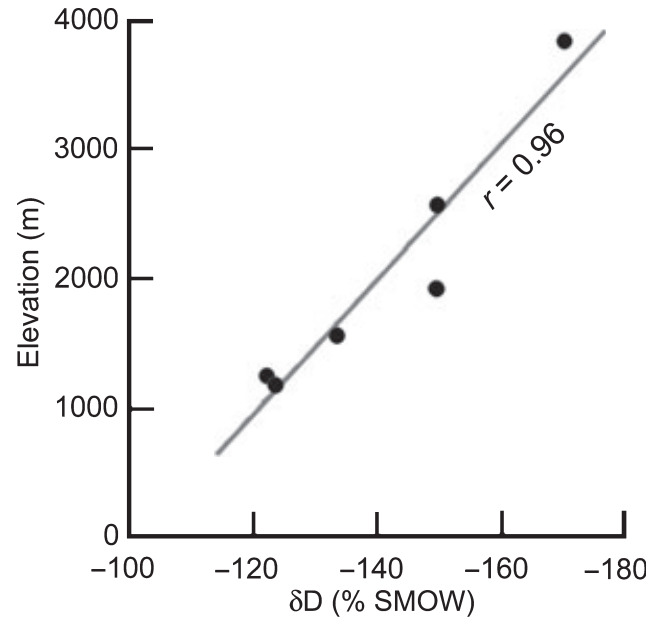

Fig. 4. Relationship between $\delta D$ and elevation immediately east of the Sierra crest. Data from Smith et al. (1979).

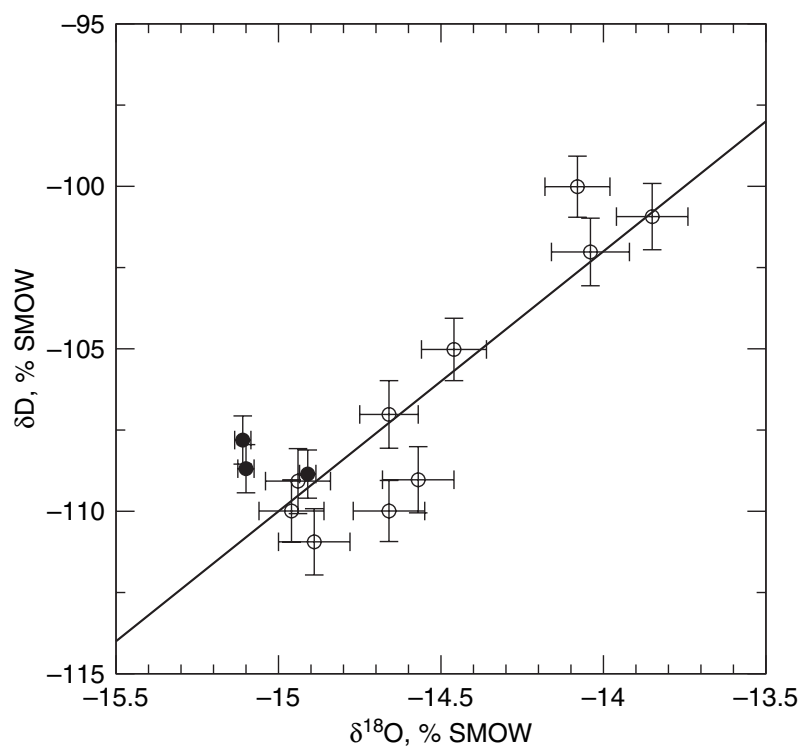

Fig. 5. $\delta^{18} \mathrm{O}$ and $\delta D$ values of water from Sagehen Springs. Solid points were measured in this study; open points are from Rademacher et al. (2002). The solid line is the global meteoric water line.

tions means that basin-scale complications such as local temperature inversions cannot be captured. Although there is significant variation in local microclimates, the observed variation in the mean annual temperature with elevation is about $3.4^{\circ} \mathrm{C} \mathrm{km}^{-1}$. A jackknife test on alternate station subgroups yields a mean slope of $4.1 \pm 1.1^{\circ} \mathrm{C} \mathrm{km}^{-1}$. This is consistent with other observational surface lapse rates (e.g. Takahashi \& Battisti 2007). We used this slope and the temperature at Spring 8 to determine a relationship between elevation and mean annual temperature in Sagehen Basin. We note that temperature lapse rates vary seasonally. To estimate the recharge temperature, we use the mean annual temperature lapse rate because infiltrating 


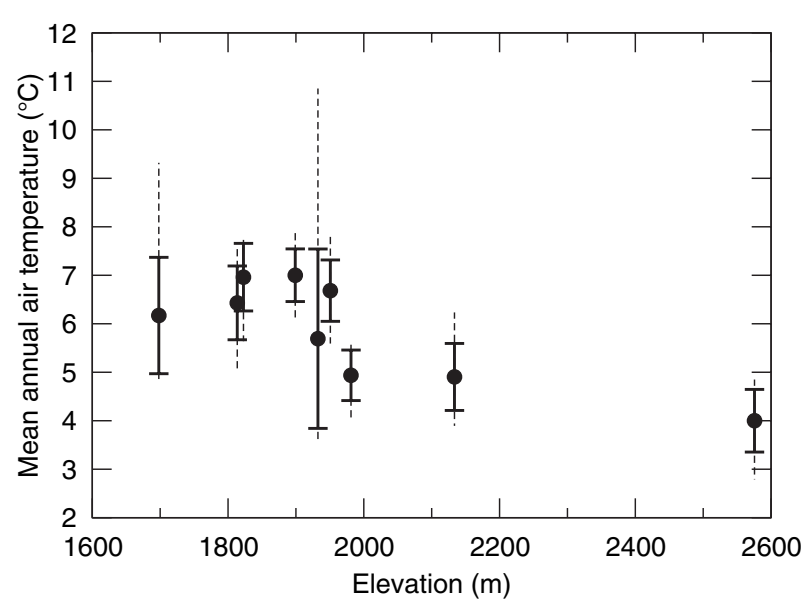

Fig. 6. Range of mean annual temperature at nine weather stations near Sagehen Basin for the period 1991-2001. Station locations are shown on Fig. 1. Thick error bars denote the standard deviation, and thin dashed lines the observed range, of mean annual temperatures during that period.

water sees a surface temperature that is close to the mean annual surface temperature. The seasonal variations in lapse rate will also contribute to seasonal isotope fractionation in precipitation, an effect already accounted for the interpretation of $\mathrm{O}$ and $\mathrm{H}$ isotopes.

In areas with winter snow cover, mean annual ground surface temperatures can be higher than mean annual air temperatures by as much as a few degrees (Signorelli \& Kohl 2004). This is caused by the insulating effect of snow and the buffering effect of soil moisture near the freezing point. In the Swiss Alps, the magnitude of this effect depends on elevation (Signorelli \& Kohl 2004). We examined soil and air temperature data from 26 SNOTEL stations in the Sierra Nevada (http://www.wcc.nrcs.usda.gov/snow/) and found that mean annual soil temperatures at $5-\mathrm{cm}$ depth were on average $0.4^{\circ} \mathrm{C}$ warmer than the corresponding mean annual air temperatures, with no observed relationship between the magnitude of the difference and elevation. Calibrating our elevation/temperature relationship with data from Spring 8 accounts for this constant temperature shift. However, there was significant variability in the observed temperature differences $\left(\sigma=1.1^{\circ} \mathrm{C}\right)$; so, we incorporated this into the errors given in Table 2 .

\section{RESULTS AND DISCUSSION}

\section{Heat flow in Sagehen springs}

Temperature, discharge and oxygen isotope measurements for springs in Sagehen Basin are listed in Table 1. For springs where continuous temperature records are available, the reported error is the standard deviation of monthly average temperatures; otherwise, it is the standard deviation of all available spot measurements. The reported error in oxygen isotopes is the standard deviation of all available spot measurements. Temporal variations in $\delta^{18} \mathrm{O}$ are significantly larger than analytical error.

The total geothermal heat flow carried by spring water is given by:

$\Delta Q_{\text {geothermal }}=\rho c q\left(\Delta T-\Delta T_{\mathrm{GPE}}\right)$

where $\rho$ is the density and $c$ the specific heat of water, $q$ is the spring discharge, $\Delta T$ is the total temperature difference between recharge temperature and discharge temperature, and $\Delta T_{\mathrm{GPE}}$ is the temperature increase expected if all the gravitational potential energy lost in moving from the infiltration elevation to the discharge elevation is converted to heat (Manga \& Kirchner 2003). $\Delta T_{\mathrm{GPE}}$ is $2.2^{\circ} \mathrm{C} \mathrm{km}^{-1}$ decrease in elevation. The energy balance represented by Equation ( 1 ) is the change in energy as water travels through both the unsaturated and saturated zones.

\begin{tabular}{|c|c|c|c|c|}
\hline Spring & $\begin{array}{l}\text { Elevation } \\
(\mathrm{m})\end{array}$ & $\begin{array}{l}\text { Discharge } \\
\text { temperature }\left({ }^{\circ} \mathrm{C}\right)\end{array}$ & $\begin{array}{l}\text { Discharge* } \\
\left(\mathrm{L} \mathrm{sec}^{-1}\right)\end{array}$ & $\begin{array}{l}\delta^{18} \mathrm{O} \% \text { SMOW } \\
\text { (number of data points) }\end{array}$ \\
\hline 2 & 2009 & $4.9 \pm 0.4$ & 0.5 & $-14.07 \pm 0.11(2)^{\dagger}$ \\
\hline 3 & 2109 & $4.6 \pm 0.2$ & 0.7 & $-13.98 \pm 0.22(1)^{*}$ \\
\hline 4 & 1999 & $4.7 \pm 0.5$ & 2.26 & $-14.48 \pm 0.18(3)^{\dagger+\star}$ \\
\hline 5 & 2012 & $5.2 \pm 0.3$ & 0.54 & $-14.60 \pm 0.19(3)^{\dagger+末}$ \\
\hline 6 & 2134 & $3.9 \pm 1.7$ & 0.09 & $-14.46 \pm 0.15(2)^{\dagger+末}$ \\
\hline 7 & 1987 & $8.8 \pm 0.6$ & $>1.91$ & $-14.92 \pm 0.15(5)^{\dagger,+. \S}$ \\
\hline 8 & 2394 & $3.2 \pm 0.1$ & 1.4 & $-13.99 \pm 0.15(4)^{\dagger, 末}$ \\
\hline 9 & 1995 & $6.7 \pm 1.2$ & 0.4 & $-14.05 \pm 0.68(3)^{\dagger+末}$ \\
\hline 10 & 2068 & $8.3 \pm 1.1$ & 0.4 & $-14.15 \pm 0.39(3)^{\dagger+末}$ \\
\hline 11 & 1989 & $6.0 \pm 0.02$ & 1.9 & $-14.88 \pm 0.14(4)^{\dagger+, \S}$ \\
\hline 13 & 2147 & $6.1 \pm 0.04$ & 1.6 & $-14.79 \pm 0.16(3)^{\dagger,+, \S}$ \\
\hline
\end{tabular}

For Spring 3, where only one stable isotope datum was available, we assumed an error of $\pm 0.2 \%$ roughly consistent with observed temporal variations in the basin's other springs.

*Erman \& Erman (1992).

$\dagger$ Rademacher (2002).

tRademacher et al. (2002).

§This study. 
Using the data summarized in Table 2, the total estimated geothermal heat flow discharged by the studied springs in Sagehen Basin is $110 \pm 22 \mathrm{~kW}$. The uncertainty of the heat discharged at individual springs is quite large, comparable with the value for most springs. The comparatively small uncertainty in the total is due to the total being dominated by discharge from a small number of springs (Springs 7, 11 and 13).

The total groundwater discharge from the Sagehen Basin can be estimated from the base flow of Sagehen Creek during late summer and early fall (0.04$0.11 \mathrm{~m}^{3} \mathrm{sec}^{-1}$; USGS gage 10343500, http://waterdata. usgs.gov/nwis/). The total discharge from springs in this study is approximately $10-20 \%$ of this value. The discharge-weighted mean age of spring water in this study is 27 years, approximately the same as the average age of water in Sagehen Creek during periods of base flow (Rademacher et al. 2005). Assuming that the springs studied are representative of the amount of geothermal heat carried by groundwater discharged in the basin as a whole, we estimate that the total heat flow carried by groundwater in the Sagehen Basin is 490-1100 kW. Averaging the total heat flow over the total area of Sagehen Basin (approximately $27 \mathrm{~km}^{2}$ ) yields a heat flow of approximately $20-40 \mathrm{~mW} \mathrm{~m}^{-2}$. Our procedure assumes that groundwater flow occurs uniformly over the entire basin. If flow is concentrated in a portion of the basin, the actual heat flow would be proportionately greater than $20-40 \mathrm{~mW} \mathrm{~m}^{-2}$.

\section{Implications for Sagehen Basin hydrogeology}

\section{Recharge locations}

Estimated recharge elevations of waters from several springs in the Sagehen Basin are too high for the water to have been recharged within the basin itself. One possible explanation is that the elevation at which precipitation over Sagehen Basin condenses is not linearly related to the elevation at which it hits the ground or the relationship does not have the same slope as the stations studied by Smith et al. (1979).
Another possibility is that some of the water originated in higher elevation basins. Güler \& Thyne (2006) found evidence for interbasin flow in the southern Sierra Nevada, and Sylvester (2007) has suggested that groundwater from Independence Lake might feed springs on the western side of the basin. While there is no direct evidence for this, the possibility of interbasin flow is a concern in any area where the hydrogeology has not been studied in detail. If there is significant interbasin flow, then our heat flow estimate would need to be reduced, as the springs in Sagehen Basin would be scavenging heat from a larger area.

In general, we find that groundwater recharge in the Sagehen Basin, at least that discharged at the springs, probably occurs near the high-elevation basin rim where volcanic rocks outcrop.

\section{Temporal versus spatial origin for $\delta^{18} \mathrm{O}$ variability}

Although Smith et al. (1979) found a correlation between elevation and isotopic composition of precipitation, including snow, on the lee side of the Sierras, the presence or absence of such a correlation for precipitation within the Sagehen Basin has not been established. In this study, we attribute the observed variations in $\delta^{18} \mathrm{O}$ to spatial variations in precipitation. Rademacher et al. (2002), however, attributed them to year-to-year variations in weather patterns, which should reflect decadal-scale climate change. Both temporal and spatial variations in $\delta^{18} \mathrm{O}$ are potentially important, and there are currently not enough data available to distinguish between them.

Rademacher et al. (2002) observed a correlation between age and $\delta^{18} \mathrm{O}$, with younger water being isotopically light. We posit that this occurs because the isotopically light water precipitated at high elevations must travel farther to its discharge point than isotopically heavy water from low elevations. If this is the case, there should be a correlation between our estimated change in elevation and the age of the water; that relationship is shown in Fig. 7. However, because our estimated change in elevation for spring water is related to its $\delta^{18} \mathrm{O}$, this correlation is not sufficient to allow us to distinguish between the two interpretations.
Table 2 Calculated heat flow in Sagehen Basin Springs; Spring 8 does not appear as it is used for calibration.

\begin{tabular}{cllllc}
\hline Spring & Recharge elevation $(\mathrm{m})$ & Recharge temperature $\left({ }^{\circ} \mathrm{C}\right)$ & $\Delta T\left({ }^{\circ} \mathrm{C}\right)$ & $\Delta T_{\mathrm{GPE}}\left({ }^{\circ} \mathrm{C}\right)$ & $\mathrm{Q}_{\text {geothermal }}(\mathrm{kW})$ \\
\hline 2 & $2440 \pm 80$ & $3.0 \pm 1.1$ & $1.9 \pm 1.2$ & 1.0 & $1.8 \pm 2.6$ \\
3 & $2390 \pm 120$ & $3.2 \pm 1.1$ & $1.4 \pm 1.1$ & 0.7 & $2.1 \pm 3.6$ \\
4 & $2620 \pm 110$ & $2.1 \pm 1.1$ & $2.6 \pm 1.2$ & 1.5 & $9.8 \pm 12$ \\
5 & $2680 \pm 110$ & $2.0 \pm 1.1$ & $3.2 \pm 1.2$ & 1.6 & $3.6 \pm 2.9$ \\
6 & $2610 \pm 100$ & $2.5 \pm 1.1$ & $1.4 \pm 2.0$ & 1.0 & $0.2 \pm 0.8$ \\
7 & $2817 \pm 90$ & $1.4 \pm 1.2$ & $7.4 \pm 1.3$ & 2.0 & $43 \pm 11$ \\
9 & $2420 \pm 320$ & $2.8 \pm 1.1$ & $3.9 \pm 1.6$ & 1.2 & $4.6 \pm 3.5$ \\
10 & $2470 \pm 190$ & $3.1 \pm 1.2$ & $5.2 \pm 1.6$ & 0.8 & $7.3 \pm 2.9$ \\
11 & $2800 \pm 90$ & $1.6 \pm 1.2$ & $4.4 \pm 1.2$ & 1.9 & $20 \pm 9.9$ \\
13 & $2760 \pm 110$ & $1.6 \pm 1.2$ & $4.5 \pm 1.2$ & 1.5 & $20 \pm 8.3$ \\
Total & & & & & $110 \pm 22$ \\
\hline
\end{tabular}




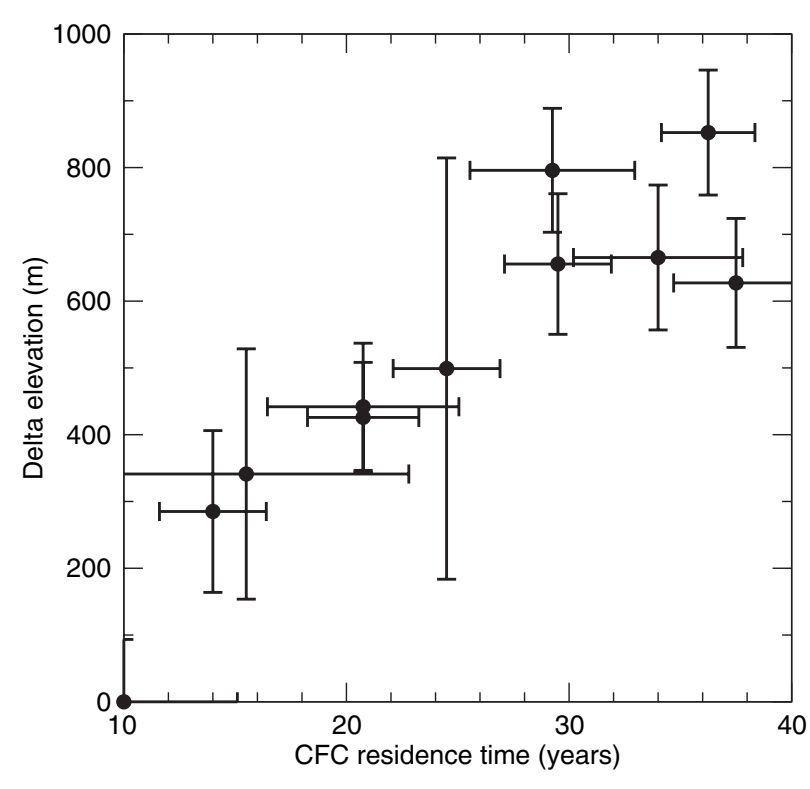

Fig. 7. Relationship between the recharge-discharge elevation difference found in this study, and average apparent CFC age given by Rademacher et al. (2002).

\section{Depth of circulation}

The subsurface hydrogeology is not known; so, we are limited in our ability to infer the nature of groundwater flow paths and, importantly, the depth to which the water circulates and removes geothermal heat. However, the lack of discernible annual temperature variations provides a lower bound on the depth at which groundwater circulates. In a conductive half space, periodic temperature variations decay to $1 / \mathrm{e}$ of their initial amplitude at a depth given by:

$\delta=\sqrt{\kappa t / \pi}$

where $\kappa$ is the thermal diffusivity of the soil and $t$ the characteristic timescale of the temperature variation.

Seasonal temperature variations in the Sagehen Basin are approximately $17^{\circ} \mathrm{C}$ (mean January temperature $-2.9^{\circ} \mathrm{C}$, mean July temperature $14.5^{\circ} \mathrm{C}$ ). When the effects of mixing with surface snow and meltwater are ignored, temperatures in Springs 11 and 13 are constant to within less than $0.1^{\circ} \mathrm{C}$. This indicates that the dominant flow path of water feeding these springs is at least five skin depths below the ground surface, and that the water ascends quickly enough, with velocity $\gg \kappa / \delta$, to remain isothermal while feeding the spring. The thermal diffusivity of soils can vary by more than an order of magnitude, but assuming a value of $\kappa=1 \times 10^{-7}-1 \times 10^{-6} \mathrm{~m}^{2} \mathrm{sec}^{-1} \quad$ (e.g. Ochsner et al. 2001), one skin depth is approximately $1-3 \mathrm{~m}$. Thus, the dominant flow path for these springs must be at least $5 \mathrm{~m}$ below ground surface.

Additionally, temperatures in several Sagehen springs are $1-2^{\circ} \mathrm{C}$ above the expected mean annual temperature at their discharge elevation. To attain these temperatures in a conductive geothermal gradient of approximately $0.01^{\circ} \mathrm{C} \mathrm{m}^{-1}$, the water must circulate to depths exceeding $100 \mathrm{~m}$ or contain a mixture of deeply circulating and shallower components. A lack of excess ${ }^{4} \mathrm{He}$ in Sagehen springs indicates that the latter scenario is unlikely (Rademacher et al. 2001).

\section{Surface water mixing}

During snow melt, Spring 13 develops a small diurnal temperature oscillation. We assume that this is due to mixing of stable temperature groundwater with surface run-off and/or very shallow groundwater. The magnitude of daily temperature variations in Spring 13 can provide a lower limit on the amount of mixing that occurs.

Surface water temperature fluctuations will always be less than air temperature fluctuations. If we assume that surface water temperature is the same as air temperature, which fluctuates between about $20^{\circ} \mathrm{C}$ during the day and $0^{\circ} \mathrm{C}$ at night, then the observed diurnal fluctuations of approximately $0.2-0.4^{\circ} \mathrm{C}$ require that at least $2 \%$ of the flow from Spring 13 be surface water.

\section{Darcy fluxes and permeability}

Lower-bound hydraulic conductivities within the Sagehen Basin can be estimated from the distance between a spring and the nearest occurrence of the recharge elevation, the hydraulic head $H$ generated by this elevation difference, and the spring water age:

$v_{\mathrm{d}}=\frac{\phi_{\text {eff }}[\text { horizontal distance traveled }]}{[\text { spring water age }]}=-K \frac{\mathrm{d} H}{\mathrm{~d} x}$

where $v_{\mathrm{d}}$ is the Darcy flux, $\phi_{\text {eff }}$ the effective porosity and $K$ the hydraulic conductivity. We can constrain the effective porosity using the average groundwater residence time $T$ and recharge rate. In an aquifer of average thickness $b$ which is recharged uniformly at a rate $N$, these are related as follows (Manga 2001):

$T=\frac{b \phi_{\mathrm{eff}}}{N}$

If the discharge during periods of base flow at Sagehen Creek is averaged over the basin area, the resulting average recharge is $1-4 \times 10^{-9} \mathrm{~m} \mathrm{sec}^{-1}\left(3-10 \mathrm{~cm} \mathrm{year}^{-1}\right)$. This implies that $10 \%$ or less of the total precipitation in the Sagehen Basin is recharged to the aquifer. By contrast, the average discharge from Sagehen Creek during September, at the end of the dry season, is $22 \%$ of the average discharge over the whole year; this ratio is more consistent with estimated infiltration in Nevada (Watson et al. 1976). If this represents the proportion of precipitation that recharges the aquifer, the average recharge will be higher $\left(6 \times 10^{-9} \mathrm{~m} \mathrm{sec}^{-1}\right)$. 
The mean age of water in Sagehen Creek during periods of base flow is 28 years (Rademacher et al. 2005). As discussed in the Depth of circulation section, the aquifer ought to be at a minimum of several tens of meters thick; the effective porosity in the Sagehen Basin must therefore be less than $10 \%$. Effective porosities of a few percent have been found in other weathered andesites (Karpuz \& Pasamehmetoglu 1997) and are also appropriate for finerich till. We therefore assume an effective porosity of 0.05 . This yields a Darcy flux of $3 \times 10^{-8}-5 \times 10^{-7} \mathrm{~m} \mathrm{sec}^{-1}$ $\left(100-1600 \mathrm{~cm} \mathrm{year}^{-1}\right)$, with an average value of $3 \times 10^{-7}$ $\mathrm{m} \mathrm{sec}^{-1}\left(600 \mathrm{~cm} \mathrm{year}^{-1}\right)$ for all springs in the Sagehen Basin. This implies average hydraulic conductivities within the basin of $10^{-8}-10^{-6} \mathrm{~m} \mathrm{sec}^{-1}$ and hydraulic permeabilities of at least $10^{-15}-10^{-13} \mathrm{~m}^{2}$, consistent with measured permeabilities in andesite (Saar \& Manga 1999).

Note that a mean age of 28 years, an effective porosity of 0.05 and recharge of $3-10 \mathrm{~cm} \mathrm{year}^{-1}$ imply a mean thickness of the saturated flow paths of $17-56 \mathrm{~m}$ and hence circulation depths that exceed this range.

\section{Model of advective heat transport}

To determine whether advective (shallow) heat transport by groundwater is the primary component of the total geothermal heat flow budget, we develop an analytical model for steady-state flow in the basin's deepest (and therefore the highest temperature) flow paths. A schematic diagram is shown in Fig. 8.

We assume that the basement rocks underlying the Sagehen Basin form an impermeable block. Water recharges at the left of the model basin and discharges at the right. It flows for distance $L$ along the bottom of the basin in a zone of thickness $b$ at a depth $a$. For simplicity, we assume constant Darcy flux and porosity, which implies that the recharge zone also has width $b$. We further assume that only vertical heat conduction takes place above the aquifer, that the temperature gradient within the aquifer is parallel to groundwater flow and that only insignificant heat transfer occurs between the recharge zone and the surrounding rock.

The heat flow from below is $q_{i}$. We can define a thermal Péclet number:

$\operatorname{Pe}=\frac{\rho c v a}{\lambda}$

where $\rho$ is the density of water, $c$ its specific heat, $v$ the Darcy flux and $\lambda$ the bulk thermal conductivity of the aquifer and overlying rock. This Péclet number relates the rate at which heat is advected horizontally across the aquifer to the rate at which it is conducted to the surface.

The governing equation for a one-dimensional recharge zone (e.g. Bredehoeft \& Papadopulos 1965) is:

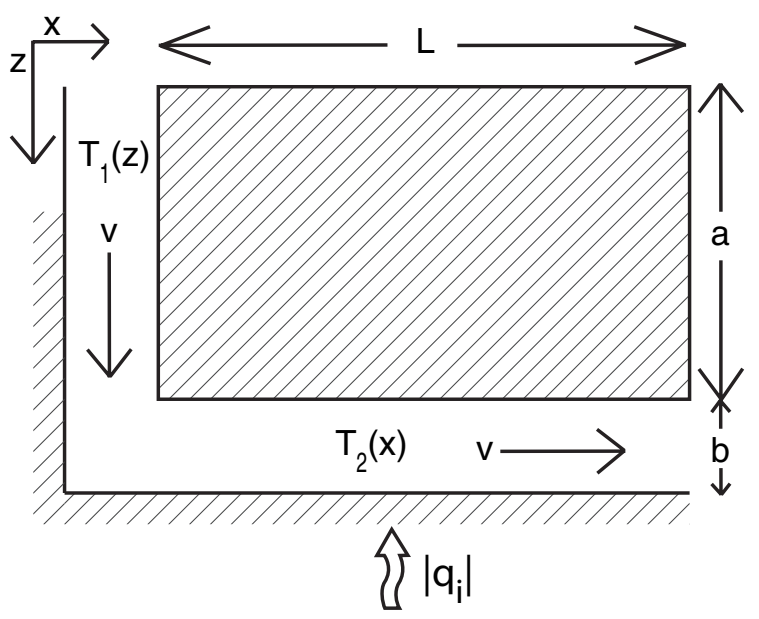

Fig. 8. A simplified groundwater flow and heat transport model for the deepest flow paths in Sagehen Basin.

$\lambda \frac{\mathrm{d}^{2} T}{\mathrm{~d} z^{2}}=\rho c v \frac{\mathrm{d} T}{\mathrm{~d} z}$

The recharge zone has a constant temperature $T_{0}$ at the top, and a constant heat flow $q_{i}$ at the bottom. Without loss of generality, we can set $T_{0}=0$. The solution to Equation (6) for these boundary conditions is:

$T_{1}(z)=\frac{q_{i} a}{\operatorname{Pe} \times \lambda} \mathrm{e}^{-\mathrm{Pe}}\left[1-\mathrm{e}^{\mathrm{Pe}(z / a)}\right]$

Čermak \& Jetel (1985) give the solution for steady-state temperature in a horizontal aquifer of thickness $b$ with a constant heat flux at its base:

$T_{2}(x)=\frac{q_{i} a}{\lambda}\left(1-\mathrm{e}^{-n x}\right)+T_{1}(a) \mathrm{e}^{-n x}$

where

$n=-\frac{\operatorname{Pe}}{2 a}\left[1-\sqrt{1+\frac{4 a}{b \times \mathrm{Pe}^{2}}}\right]$

Substituting for $T_{1}(a)$ results in:

$T_{2}(L)=\frac{q_{i} a}{\lambda}\left[1-\mathrm{e}^{-n L}+\frac{\mathrm{e}^{-n L}}{\mathrm{Pe}}\left(\mathrm{e}^{-\mathrm{Pe}}-\mathrm{l}\right)\right]$

The total heat transported by groundwater in this model is given by:

$Q_{a}=\rho c v b T_{2}(L)$

Substituting for $T_{2}$ and $T_{1}$, the ratio of the heat flow carried by groundwater $Q_{a}$ to the total heat flow $Q_{i}$ is:

$\frac{Q_{a}}{Q_{i}}=\frac{\operatorname{Pe} \times b}{L+b}\left[1-\mathrm{e}^{-n L}-\frac{\mathrm{e}^{-n L}}{\operatorname{Pe}}\left(1-\mathrm{e}^{-\mathrm{Pe}}\right)\right]$

Figure 9 shows the calculated ratio of advected heat to total heat for varying aquifer thicknesses $(b)$ and depths 

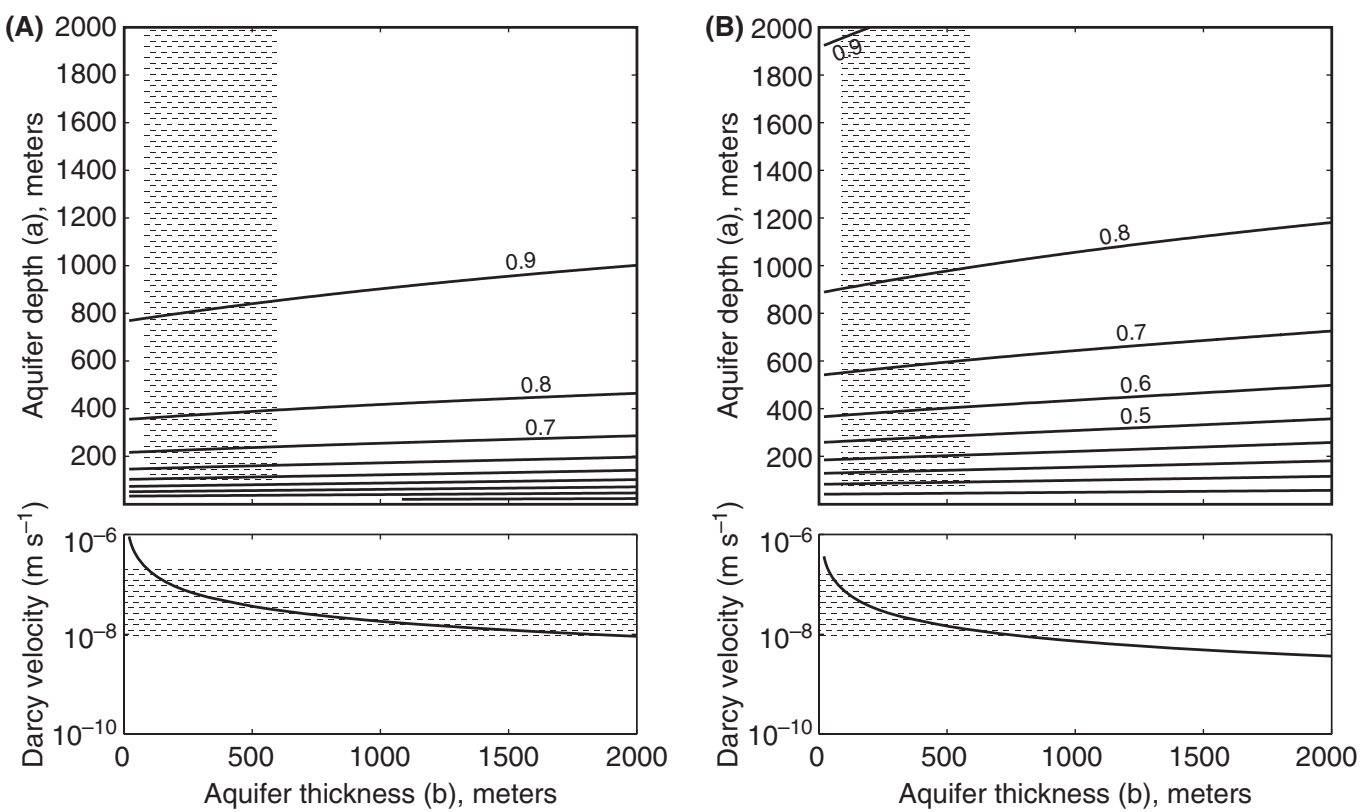

Fig. 9. Ratio of advected heat to total heat, assuming an aquifer length of $5 \mathrm{~km}$, width of $5.5 \mathrm{~km}$, and a constant discharge of (A) $0.1 \mathrm{~m}^{3}$ sec ${ }^{-1}$, and (B) $0.04 \mathrm{~m}^{3} \mathrm{sec}^{-1}$. Bottom panels show the Darcy velocity required to maintain the given discharge. The shaded regions on each graph represent probably approximate aquifer dimensions for the Sagehen Basin.

(a), assuming a constant length $L$ and width (perpendicular to the page) of $5 \mathrm{~km}$ and $5.5 \mathrm{~km}$, respectively, similar to the dimensions of Sagehen Basin. We allowed specific discharge to vary with aquifer thickness in order to maintain the observed discharge of 0.04 $0.1 \mathrm{~m}^{3} \mathrm{sec}^{-1}$.

The subsurface structure of the Sagehen Basin is not well characterized. However, we can constrain the average aquifer thickness with a mass balance equation. For steady-state flow

$q=b \delta v_{\mathrm{d}}$

where $q$ is the total discharge and $\delta$ the model width, which is equal to the total area of Sagehen Basin divided by $L$. Using the average Darcy flux of $2 \times 10^{-7} \mathrm{~m} \mathrm{sec}^{-1}$, we find that $b$ is in the order of 40-90 m. Using the highest and lowest Darcy fluxes found in the Implications for Sagehen Basin hydrogeology section, we find a range of aquifer thickness of approximately 40-600 m.

The amount of advected heat primarily depends on the depth at which groundwater circulates. As discussed in the Depth of circulation section, the mean age of the water and lack of seasonal temperature variations require the circulation depth to be at least $10 \mathrm{~m}$ and it could exceed $100 \mathrm{~m}$. Thicknesses of $10^{2} \mathrm{~m}$ are similar to thicknesses of the volcanic units in the basin (Sylvester 2007). Within this range of aquifer depths, anywhere from $20 \%$ to $>90 \%$ of the total geothermal heat flow in the basin may be discharged by groundwater.

\section{IMPLICATIONS FOR SIERRA HEAT FLOW}

Using empirical correlations between elevation and the stable isotope composition of precipitation, and between elevation and temperature, we have inferred that the geothermal heat carried by springs in the Sagehen Basin is $20-40 \mathrm{~mW} \mathrm{~m}^{-2}$, similar to the heat flow measured in boreholes in other parts of the Sierra Nevada. The exact proportion of the total geothermal heat flow represented by this value depends on the distribution of groundwater flow in the basin, which is unknown. Based on a simplified $2 \mathrm{D}$ model of groundwater flow and heat transport, groundwater may represent $20 \%$ to $>90 \%$ of the total heat flow in the Sagehen Basin. The true heat flow in the basin may therefore be $>100 \mathrm{~mW} \mathrm{~m}^{-2}$, significantly higher than that observed in boreholes elsewhere in the Sierras. The average heat flow in Lake Tahoe is $67 \mathrm{~mW} \mathrm{~m}^{-2}$ (Henyey \& Lee 1976); so, it is plausible that heat flow in the Sagehen Basin could be higher than elsewhere in the Sierra.

The model used here is not appropriate for more than a rough estimate of the significance of groundwater to the total geothermal heat budget. A more detailed flow model of the basin is required to specify both the total heat carried by groundwater (the greatest error in this measurement is the factor of two uncertainties in groundwater discharge) and the fraction of the total geothermal heat budget it represents. Based on this study, we are only capable of concluding that groundwater transports a 
Table 3 Standard errors.

\begin{tabular}{lll}
\hline Quantity & Value & Relevant sections of the paper \\
\hline$\sigma_{m_{\mathrm{t}}}$ & $1.1^{\circ} \mathrm{C} \mathrm{km}^{-1}$ & Recharge temperature \\
$\sigma_{m_{\mathrm{r}}}$ & $0.000189 \mathrm{~km} / \%$ & Recharge elevation \\
$\sigma_{\mathrm{O}_{8}}$ & $0.15 \%$ & Recharge elevation and Table 1 \\
$\sigma_{T_{8}}$ & $0.1^{\circ} \mathrm{C}$ & Heat flow in Sagehen springs and Table 1 \\
$\sigma_{T_{i}}$ & $1.1^{\circ} \mathrm{C}$ & Heat flow in Sagehen springs and Table 1 \\
$\sigma_{\mathrm{O}_{\mathrm{s}}}$ & Varies by spring & Heat flow in Sagehen springs and Table 1 \\
$\sigma_{T_{\mathrm{s}}}$ & Varies by spring & Heat flow in Sagehen springs and Table 1 \\
\hline
\end{tabular}

significant portion of the heat flow in Sagehen Basin. As we do not know the depth of circulation, and we have no deep boreholes in the basin in which temperature can be measured, we cannot distinguish between two possible endmember implications of the heat discharge estimates. The first possibility is that the heat discharge we measure reflects a shift in the mode of heat transfer from conduction to advection at shallow depths $(<100 \mathrm{~m})$. In this case, our conclusion that groundwater flow transports significant amounts of heat does not influence heat flow estimates based on deeper borehole measurements. The second possibility is that springs reflect groundwater circulation within the upper few hundred meters where borehole temperatures are made, and hence that the actual geothermal heat flow needs to be augmented by the amount discharged by groundwater. This second case challenges two paradigms: that heat flow in the Sierras is low, and that they are well-described by a linear heat flow-heat production relation.

Distinguishing between these two possible interpretations requires addressing two issues. First, how deep does spring water circulate? Second, how representative is the Sagehen Basin? Groundwater in the Sagehen Basin probably flows through highly permeable volcanic deposits. It is in such permeable units where advective removable of heat is most effective (e.g. Forster and Smith, 1988; Ingebritsen et al. 1989; Manga 1998). As such deposits are not widespread in the Sierra Nevada, we caution that the role of groundwater in heat transport in the Sagehen Basin may not be representative of that in the rest of the Sierra Nevada. Similar temperature and isotopic measurements are necessary elsewhere to identify geothermal heat discharged at springs.

\section{ACKNOWLEDGEMENTS}

This study was partially supported by the Larsen Foundation. We thank Laura Rademacher for leading a field trip to the snow-covered Sagehen Basin during the winter of 2004 and Sarah Godsey for helpful discussions of basin hydrology. We thank three reviewers and editor Ingebritsen for helpful suggestions and constructive criticism.

\section{APPENDIX}

\section{Error analysis for Sagehen Basin heat flow}

We calculate the geothermal change in temperature for springs in Sagehen Basin as:

$\Delta T_{\mathrm{geo}}=\Delta T_{\mathrm{obs}}-\Delta T_{\mathrm{GPE}}$

where $\Delta T_{\mathrm{obs}}$ is the estimated recharge temperature minus the observed discharge temperature and $\Delta T_{\mathrm{GPE}}$ is the temperature increase if all of the gravitational potential energy associated with the difference between recharge and discharge elevations is turned into heat. Thus,

$\Delta T_{\text {geo }}=\left[T\left(E_{\mathrm{r}}\right)-T_{\mathrm{s}}\right]-\rho g\left(E_{\mathrm{r}}-E_{\mathrm{s}}\right)$,

where $E_{\mathrm{r}}$ is the recharge elevation for each spring (see Equations 20-21 and Table 2), $E_{\mathrm{s}}$ the spring elevation, $T\left(E_{\mathrm{r}}\right)$ the mean annual temperature at the recharge elevation (see Equation 3 ) and $T_{\mathrm{s}}$ the observed spring temperature (see Table 1). The temperature at the recharge elevation is given by:

$T\left(E_{\mathrm{r}}\right)=m_{\mathrm{t}} E_{\mathrm{r}}+b_{\mathrm{t}}$,

where $m_{\mathrm{t}}$ is empirically determined using historical weather records (see the Recharge temperature section), and $b_{\mathrm{t}}$ is determined by using Spring 8 as a calibration point:

$b_{\mathrm{t}}=T_{8}-m_{\mathrm{t}} E_{8}$,

and thus,

$\Delta T_{\text {geo }}=m_{\mathrm{t}} E_{\mathrm{r}}+T_{8}-m_{\mathrm{t}} E_{8}-T_{\mathrm{s}}-\rho g\left(E_{\mathrm{r}}-E-s\right)$

The recharge elevation is:

$E_{\mathrm{r}}=m_{\mathrm{r}} O_{\mathrm{s}}+b_{\mathrm{r}}$

where $1 / m_{\mathrm{r}}$ is given by Smith et al. (1979), and $b_{\mathrm{r}}$ is determined by using Spring 8 as a calibration point:

$b_{\mathrm{r}}=E_{8}-m_{\mathrm{r}} O_{8}=E_{8}-\frac{O_{8}}{2.2 \% \mathrm{~km}^{-1}}$

where $E_{8}$ and $O_{8}$ are the elevation and $\delta^{18} O$, respectively, of Spring 8. Therefore,

$$
\begin{aligned}
\Delta T_{\mathrm{geo}}= & m_{\mathrm{t}}\left(m_{\mathrm{r}} O_{\mathrm{s}}+E_{8}-m_{\mathrm{r}} O_{8}\right)+T_{8}-m_{\mathrm{t}} E_{8}-T_{\mathrm{s}} \\
& -\rho g\left(m_{\mathrm{r}} O_{\mathrm{s}}+E_{8}-m_{\mathrm{r}} O_{8}-E_{\mathrm{s}}\right)
\end{aligned}
$$

The standard error for a multivariable function $F\left(x_{1}, x_{2}, x_{3}, \ldots\right)$ is given in Taylor (1982):

$\sigma_{F}^{2}=\left(\frac{\partial F}{\partial x_{1}}\right)^{2} \sigma_{x_{1}}^{2}+\left(\frac{\partial F}{\partial x_{2}}\right)^{2} \sigma_{x_{2}}^{2}+\left(\frac{\partial F}{\partial x_{3}}\right)^{2} \sigma_{x_{3}}^{2}+\cdots$ 
Therefore, the error in geothermal temperature increase is

$$
\begin{aligned}
\sigma_{T_{\text {geo }}}^{2} & =\left(\frac{\partial T_{\text {geo }}}{\partial m_{\mathrm{t}}} \sigma_{m_{\mathrm{t}}}\right)^{2}+\left(\frac{\partial T_{\text {geo }}}{\partial m_{\mathrm{r}}} \sigma_{m_{\mathrm{r}}}\right)^{2}+\left(\frac{\partial T_{\text {geo }}}{\partial O_{\mathrm{s}}} \sigma_{O_{\mathrm{s}}}\right)^{2} \\
& +\left(\frac{\partial T_{\text {geo }}}{\partial O_{8}} \sigma_{O_{8}}\right)^{2}+\left(\frac{\partial T_{\text {geo }}}{\partial T_{8}} \sigma_{T_{8}}\right)^{2}+\left(\frac{\partial T_{\text {geo }}}{\partial T_{\mathrm{s}}} \sigma_{T_{\mathrm{s}}}\right)^{2}
\end{aligned}
$$

or

$$
\begin{aligned}
\sigma_{T_{\text {geo }}}^{2}= & {\left[m_{\mathrm{r}}\left(O_{\mathrm{s}}-O_{8}\right) \sigma_{m_{\mathrm{t}}}\right]^{2}+\left[\left(m_{\mathrm{t}}+\rho g\right)\left(O_{8}-O_{\mathrm{s}}\right) \sigma_{m_{\mathrm{r}}}\right]^{2} } \\
& +\left[m_{\mathrm{r}}\left(m_{\mathrm{t}}-\rho g\right) \sigma_{O_{\mathrm{s}}}\right]^{2}+\left[m_{\mathrm{r}}\left(\rho g-m_{\mathrm{t}}\right) \sigma_{O 8}\right]^{2} \\
& +\sigma_{T_{8}}^{2}+\sigma_{T_{\mathrm{s}}}^{2}+\sigma_{T_{i}}^{2}
\end{aligned}
$$

where $\sigma_{T_{i}}^{2}$ is an additional uncertainty associated with the magnitude of the insulating effect of snow. The standard errors for each variable are summarized in Table 3 .

\section{REFERENCES}

Blumhagen ED, Clark J (2008) Carbon sources and signals through time in an Alpine groundwater Basin, Sagehen California. Applied Geochemistry, 23, 2284-91.

Bodri B, Rybach L (1998) Influence of topographically driven convection on heat flow in the Swiss Alps: a model study. Tectonophysics, 291, 19-27.

Brady RJ, Ducea MN, Kidder SB, Saleeby JB (2006) The distribution of radiogenic heat production as a function of depth in the Sierra Nevada Batholith, California. Lithos, 86, 229-44.

Bredehoeft J, Papadopulos I (1965) Rates of vertical groundwater movement estimated from the earth's thermal profile. Water Resources Research, 1, 325-29.

Carlson RW, Pearson DG, James DE (2005) Physical, chemical, and chronological characteristics of continental mantle. Reviews of Geophysics, 43, RG1001.

Cermak V, Jetel J (1985) Heat flow and ground water movement in the Bohemian Cretaceous Basin (Czechoslovakia). Journal of Geodynamics, 4, 285-303.

Craig H (1961) Isotopic variations in meteoric waters. Science, $133,1702-03$.

Dumitru TA (1990) Subnormal cenozoic geothermal gradients in the extinct Sierra Nevada magmatic arc - consequences of Laramide and post-Laramide shallow-angle subduction. Journal of Geophysical Research-Solid Earth and Planets, 95, 4925-41.

English JM, Johnston ST, Wang K (2003) Thermal modelling of the Laramide orogeny: testing the flat-slab subduction hypothesis. Earth and Planetary Science Letters, 214, 619-32.

Erkan K, Blackwell D (2006) Thermal implications of the cessation of subduction in the Sierra Nevada and Baja California arcs Eos Trans. AGU, 87 Fall Meet. Suppl., Abstract S43A-1357.

Erman NA, Erman DC (1992) Physical/chemical profiles of Sierra Nevada cold springs before and during drought. In: The History of Water: Eastern Sierra Nevada, Owens Valley, White-Inyo Mountains, (eds Hall CA Jr, Doyle-Jones V, Widawski B) White Mountain Research Station Symposium, 4, 428-439.

Forster C, Smith L (1988) Groundwater flow systems in mountainous terrain 2: controlling factors. Water Resources Research, 24, 1011-23.

Güler C, Thyne GD (2006) Statistical clustering of major solutes: use as a tracer for evaluating interbasin groundwater flow into
Indian Wells Valley, California. Environmental and Engineering Geoscience, 12, 53-65.

Henyey T, Lee T (1976) Heat flow in Lake Tahoe, CaliforniaNevada, and the Sierra Nevada-Basin and Range transition. Geological Society of America Bulletin, 87, 1179-87.

Ingebritsen SE, Sherrod DR, Mariner RH (1989) Heat flow and hydrothermal circulation in the Cascade range, north-central Oregon. Science, 243, 1458-62.

Jaupart C, Mareschal J (1999) The thermal structure and thickness of continental roots. Lithos, 48, 93-114.

Karpuz C, Pasamehmetoglu AG (1997) Field characterisation of weathered Ankara andesites. Engineering Geology, 46, 1-17.

Lachenbruch AH (1968) Preliminary geothermal model of the Sierra Nevada. Journal of Geophysical Research, 73, 6977-89.

Lachenbruch AH, Sass JH, Munroe RJ, Moses Jr TH (1976) Geothermal setting and simple heat conduction models for the Long Valley caldera. Journal of Geophysical Research, 81, 76984

Manga M (1998) Advective heat transport by low-temperature discharge in the Oregon cascades. Geology, 26, 799-802.

Manga M (2001) Using springs to study groundwater flow and active geologic processes. Annual Review of Earth and Planetary Science, 29, 201-28.

Manga M, Kirchner JW (2003) Interpreting the temperature of water at cold springs and the importance of gravitational potential energy. Water Resources Research, 40, W05110.

Ochsner TE, Horton R, Ren T (2001) A new perspective on soil thermal properties. Soil Science Society of America Journal, 65, 1641-47.

Poage MA, Chamberlain CP (2001) Empirical relationships between elevation and the stable isotope composition of precipitation and surface waters: considerations for studies of paleoelevation change. American Journal of Science, 301, 1-15.

Rademacher LK (2002) Groundwater flowpaths, chemical weathering rates, and climate change patterns as determined using multiple environmental tracers. $\mathrm{PhD}$ thesis, University of California, Santa Barbara, CA.

Rademacher LK, Clark JF, Hudson GB, Erman DC, Erman NA (2001) Chemical evolution of shallow groundwater as recorded by springs, Sagehen Basin; Nevada County, California. Chemical Geology, 179, 37-51.

Rademacher LK, Clark J, Hudson G (2002) Temporal changes in stable isotope composition of spring waters: implications for recent changes in climate and atmospheric circulation. Geology, 30, 139-42.

Rademacher LK, Clark JF, Clow DW, Hudson GB (2005) Old groundwater influence on stream hydrochemistry and catchment response times in a small Sierra Nevada catchment: Sagehen Creek, California. Water Resources Research, 41, WR002805.

Roy RF, Blackwell DD, Birch F (1968) Heat generation of plutonic rocks and continental heat flow provinces. Earth and Planetary Science Letters, 5, 1-12.

Roy RF, Blackwell DD, Decker ER (1972). Continental heat flow, chapter 19. In: The Nature of the Solid Earth (ed. Robertson EC), pp. 506-44. McGraw Hill, New York.

Saar MO, Manga M (1999) Permeability-porosity relationship in vesicular basalts. Geophysical Research Letters, 26, 111-14.

Saltus RW, Lachenbruch AH (1991) Thermal evolution of the Sierra Nevada: tectonic implications of new heat flow data. Tectonics, 10, 325-44.

Saucedo, GJ and Wagner, DL (1992) Geologic map of the Chico quadrangle (scale 1:250000). California Division of Mines and Geology, Regional Geologic Map Series Map No. 7A. California Division of Mines and Geology, Sacramento. 
Signorelli S, Kohl T (2004) Regional ground surface temperature mapping from meteorological data. Global and Planetary Change, 40, 267-84.

Smith L, Chapman DS (1985) The influence of water table configuration on the near-surface thermal regime. Journal of Geodynamics, 4, 183-98.

Smith GI, Friedman I, Klieforth H, Hardcastle K (1979) Areal distribution of deuterium in Eastern California precipitation, 1968-1969. Journal of Applied Meteorology, 18, 172-88.

Sylvester AG, students (2007) Geology of the Sagehen Creek and Independence Lake hydrologic basins, Sierra and Nevada coun- ties, California. Available at: http://www.geol.ucsb.edu/pro jects/tahoe/Sagehen/SageAbs01.html.

Takahashi K, Battisti DS (2007) Processes controlling the mean tropical Pacific precipitation pattern. Part I. The Andes and the Eastern Pacific ITCZ. Journal of Climate, 20, 3434-51.

Taylor JR (1982) An Introduction to Error Analysis: The Study of Uncertainty in Physical Measurements. University Science Books, Sausilito, CA.

Watson P, Sinclair P, Waggoner R (1976) Quantitative evaluation of a method for estimating recharge to the desert basins of Nevada. Journal of Hydrology, 31, 335-57. 